\title{
Conspicuous Ethical Consumption
}

\author{
Pascal Stiefenhofer \\ University of Brighton, Brighton, UK \\ Email: p.stiefenhofer@brighton.ac.uk
}

How to cite this paper: Stiefenhofer, P. (2019) Conspicuous Ethical Consumption. Theoretical Economics Letters, 9, 1-8. https://doi.org/10.4236/tel.2019.91001

Received: November 28, 2018

Accepted: January 7, 2019

Published: January 10, 2019

Copyright $\odot 2019$ by author(s) and Scientific Research Publishing Inc. This work is licensed under the Creative Commons Attribution International License (CC BY 4.0).

http://creativecommons.org/licenses/by/4.0/

\begin{abstract}
This paper considers a group of consumers who have preferences over how a good is produced and distributed, rather its traits alone. Moreover, it is hypothesized that ethical preferences also depend on prices, and that prices inform consumers about the way goods are produced and distributed. The concept of conspicuous ethics is introduced in order to motivate the consumption of ethically produced goods. The paper states the assumptions and conditions representing the consumption behavior of the ethical consumer. It is shown that a price-dependent direct utility function provides the necessary structure in the characterization of the consumption behavior of the ethical consumer.
\end{abstract}

\section{Keywords}

Ethical Consumerism, Fair Trade, Ethical Preferences, Price-Dependent Preferences

\section{Introduction}

In "The Theory of the Leisure Class", Veblen [1] recognizes that the consumption of "more excellent goods" is evidence of wealth and that failure to do so becomes a mark of inferiority and demerit. Veblen's theory considers a society in which individuals carve for esteem through the consumption of conspicuous goods. He assumes that a society evolves through individuals competing for esteem relative to other members of society, and that the display of economic power drives esteem. He understands that in such an economic environment, an individual utility function, which is independent of prices, is not a suitable framework for the analysis of consumption behavior of conspicuous goods. Implicit in his formulation of the consumer, Veblen believes that prices do not only signal the scarcity of goods in the coordination of consumption allocations, but

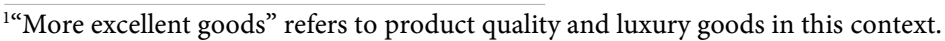


they do also affect the individual's preferences. The theory on consumption behavior when preferences depend on prices is summarized in Pollak [2].

- Preferences may depend on prices because of "snob appeal" [1].

- Preferences may depend on prices because people judge quality by its price [3].

- Price dependent preferences are also considered when individuals purchase financial assets, i.e., when money enters the utility [4].

The aim of the literature on price dependent preferences is to derive and examine the formulas for comparative statics analysis of demand functions. This requires to establish generalizations of the Slutsky equation, when normal or relative prices enter the utility of the consumer [2] [5].

In this paper, however, we ask a fundamentally different question. In particular we investigate a class of individuals who exhibit rather unusual consumption behavior according to standard economic theory, the ethical consumers. We ask the following question: Are ethical consumers best characterized by price independent or dependent preferences? Hence, the aim of this paper is to show that there are further reasons for considering price dependent preferences beyond snob appeal, judging quality by its price, and money in the utility. The focus of discussion is on the theoretical development of a model of ethical consumption, a topic only marginally encountered in the literature.

A fast growing number of consumers base their daily consumption decisions on the basis of ethical values, such as human rights, environmentally friendly production, sustainable production and distribution standards, and animal well-being [6]. Ethical consumers, hence, are consumers who beyond making rational consumption decisions on price-quantity apply certain values when making consumption decisions. According to Doane [7], ethical consumers feel responsible towards society and express these feelings via their purchasing behavior. Examples of positive ethical consumption are the purchase of fair trade, organic, and "green" products. Negative ethical consumption refers to the consumption behavior where ethical consumers express their concerns about society and environment through the boycott of purchasing unethically produced goods, i.e., goods produced under child labor, and wages below a minimum wage [6]. Another distinct property of ethical consumption is that the demand for ethically produced and distributed goods is positively correlated with prices. We illustrate this at the example of Fair Trade coffee consumption ${ }^{2}$. Basu and Hicks [8] and Pelsmacker et al. [9] analyze the stated preferences of students in the US and Canada and show that a positive relationship between Fair Trade prices and demand for ethically produced coffee exists. These results have been replicated for revealed preferences of customers of supermarkets in the same countries by Laureiro and Lotade [10] and Cranfield et al. [11]. See also [12] [13] [14] for similar results. The standard economic model fails to address these behavioral

${ }^{2}$ The positive relationship between demand for ethically produced and distributed goods and prices is observed across all market segments of ethical consumption and is not restricted to Fair Trade, and coffee. 
properties. Hence we aim at developing a model of ethical consumption satisfying:

1) Ethical consumers do not only care about the physical properties of a good, but they also care how a good is produced and distributed.

2) Ethical consumers boycott the consumption of unethically produced and distributed goods. Hence consumer may exhibit negative consumption.

3) The demand for ethically produced and distributed goods is positively correlated with prices.

The literature on the theory of ethical consumption is sparse, suggesting that the characterization of the ethical consumer is a non-trivial open problem [15]. Nevertheless, in this paper, we attempt to go a step towards such a characterization. At first instance we provide a motivation for ethical consumption. At variance to Veblen [1], who motivates the consumption of conspicuous goods by individuals striving for esteem by displaying economic power, we hypothesize that individuals carve for esteem by displaying superior ethical responsibility towards society through the consumption of ethically produced and distributed goods. This hypothesis leads to an extended preference relation, which, is distributed of the space of the physical characteristics of the goods and their associated ethical standards regarding production and distribution. We assume that such a preference relation is also dependent on prices and provide a model to test this assumption.

Our main result shows that it is necessary to characterize ethical consumers by price dependent direct utility functions. The necessity follows from a comparative analysis, showing a shift of the indifference curve given a change in the relative prices. The next section discusses the model of ethical consumption in some detail. The main result is discussed in the conclusion, which also suggests directions for future work.

\section{Modelling the Ethical Consumer}

Definition 1 Conspicuous ethics refers to an ethical consumption behavior where a consumer expresses superior ethical responsibility towards society by purchasing ethically produced and distributed goods. The ethical consumer also expresses superior ethical responsibility towards society by boycotting the consumption of unethically produced and distributed goods.

Let there be a group of socially responsible consumers represented by an index $i=1, \cdots, I$ satisfying definition 1 . There are $i=1, \cdots, L$ ethically produced and distributed consumption goods. An ethical consumption bundle is denoted by $x_{i} \in \mathbb{X}_{i}$, where $\in \mathbb{X}_{i} \subseteq \mathbb{R}_{++}^{L}$. We consider the following price normalization $q=\left(q^{1}, \cdots, q^{n}\right) \in \mathbb{S} \cup \overline{\mathbb{S}}$, where

$$
\mathbb{S}:=\left\{q \in \mathbb{R}_{++}^{L}: \sum_{l=1}^{n} q^{l}=1\right\},
$$

with its closure simplex defined by 


$$
\mathbb{S}:=\left\{q \in \mathbb{R}_{+}^{L}: \sum_{l=1}^{n} q^{l}=1\right\} .
$$

Preferences for goods may depend on prices because consumers judge quality by its price [1] or because a higher price enhances the "snob appeal" of a good [5]. Similarly, we hypothesize that preferences depend on prices because an ethically produced and distributed good enhances the "superior social responsibility" of a consumer towards society. For example, consumers are willing to pay a premium for ethically produced goods, and when market prices fall below a certain threshold, consumers are willing to pay a minimum price to producers, which guarantee ethical production. We employ a relative price hypothesis which implies that both the short run and long run demand functions are homogenous of degree zero in prices and total expenditure [2]. It is well known that such demand functions permit a meaningful welfare analysis, which is not the case when considering absolute price dependent preferences [2].

Assumption 1 For every $i=1, \cdots, I$, an ethical preference is a pair consisting of a preference ordering over an ethically produced and distributed consumption bundle $x_{i} \in \mathbb{X}_{i}$ and a relative price system $q=\left(q^{1}, \cdots, q^{n}\right) \in \mathbb{S}$, where

$$
s: S \rightarrow \mathbb{S}
$$

is a one-to-one map, disentangling the relative ethical consumption prices $p \in S \subset \mathbb{R}_{+}^{n}$ into a price index $q \in \mathbb{S}$ which enters the direct utility of the consumer.

We introduce a parameterized price dependent utility function

$$
u_{i}: \mathbb{X}_{i} \times \overline{\mathbb{S}} \rightarrow \mathbb{R}
$$

which satisfies assumption 2 .

Assumption 2 1) The parameterized utility function $u_{i}\left(x_{i} ; q\right)$ is smooth on the domain $\mathbb{X}_{i} \times \mathbb{S}$, and continuous on the domain $\left.\mathbb{X}_{i} \times \overline{\mathbb{S}} .2\right)$ The parameterized utility function is smoothly increasing w.r.t. every $x_{i}^{l}, D u_{i}\left(x_{i} ; q\right)>0$ for every $q \in \overline{\mathbb{S}} .3)$ The parameterized utility function is smoothly quasi concave. The restriction of the quadratic form $D^{2} u_{i}\left(x_{i} ; q\right)$ to the tangent hyperplane at $x_{i}^{*} \in \mathbb{X}_{i}$ to the hypersurface $\left\{x_{i} \in \mathbb{X}_{i}: u_{i}\left(x_{i} ; q\right)=u_{i}\left(x_{i}^{*} ; q\right)\right\}$ is negative definite for every $q \in \overline{\mathbb{S}}$ and $\left.x_{i}^{*} \in \mathbb{X}_{i} .4\right)$ For any $u_{i}$ there exists some $x_{i}^{*} \in \mathbb{X}_{i}$ such that the hypersurface $\left\{x_{i} \in \mathbb{X}_{i}: u_{i}\left(x_{i} ; q\right)=u_{i}^{*}\right\}$ is bounded from below for every $\left.q_{1} \in \overline{\mathbb{S}} .5\right)$ The parameterized utility function is smoothly increasing w.r.t. every $q_{i}^{l}, D u_{i}\left(x_{i} ; q\right) \geq 0$ for every $q \in \overline{\mathbb{S}}$ with strict equality for at least one $q_{i}^{l}$ (Figure 1).

Let an ethical consumer $i=1, \cdots, m$ be endowed with a vector of initial endowments $\omega_{i}=\left(\omega_{i}^{1}, \cdots, \omega_{i}^{n}\right) \in \Omega_{i} \subset \mathbb{R}_{++}$, and let his set of feasible consumption allocations be defined by

$$
\boldsymbol{B}\left(p, \omega_{i}\right):=\left\{\left(p, x_{i}\right) \in S \times \mathbb{R}_{+}^{n}: p \cdot x_{i} \leq p \cdot \omega_{i}\right\} .
$$

Let assumptions 1 and 2 hold. Then for any given ethical price system ${ }^{3} \quad p \in S$ the objective of the consumer is formalized as

${ }^{3}$ An ethical price system is a price system associated with a social label. 


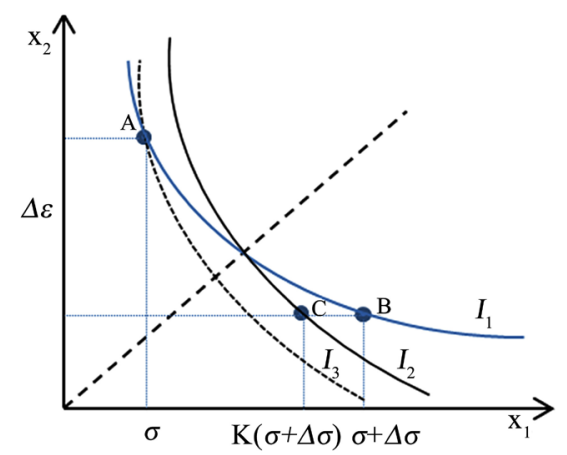

Figure 1. Result of theorem 3: Shift of price dependent preferences.

$$
\begin{aligned}
& \arg \max u_{i}\left(x_{i} ; s(p)\right) \\
& x_{i} \in \boldsymbol{B}\left(p, \omega_{i}\right)
\end{aligned}
$$

Theorem 3 An ethical consumer is characterized by a price dependent direct utility function if there is a constant $0<K\left(\Delta \epsilon_{i}\right)<2$ such that

$$
\varepsilon=\frac{q^{k}}{\operatorname{MRS}(s(p))_{l}} \frac{\partial M R S(s(p))_{l}}{\partial p^{k}}>0 .
$$

Proof. By the Fechner and Weber theorem [16], we have

$$
\begin{gathered}
\Delta \epsilon_{i}=\ln \left(\sigma_{i}+\Delta \sigma_{i}\right)-\ln \left(\sigma_{i}\right) \\
\sigma_{i}:=\frac{q^{k}}{\operatorname{MRS}(s(p))_{l}} \frac{\partial M R S(s(p))_{l}}{\partial p^{k}} \\
\Delta \sigma_{i}:=\frac{q^{k}}{M R S(s(p))_{j}} \frac{\partial M R S(s(p))_{j}}{\partial p^{k}}-\frac{q^{k}}{M R S(s(p))_{l}} \frac{\partial M R S(s(p))_{l}}{\partial p^{k}}
\end{gathered}
$$

From Equation (5), we obtain by substitution

$$
\begin{array}{r}
\Delta \epsilon_{i}=\ln \left(\frac{q^{k}}{M R S(s(p))_{l}} \frac{\partial M R S(s(p))_{l}}{\partial p^{k}}+\frac{q^{k}}{M R S(s(p))_{j}} \frac{\partial M R S(s(p))_{j}}{\partial p^{k}}\right. \\
\left.-\frac{q^{k}}{M R S(s(p))_{l}} \frac{\partial M R S(s(p))_{l}}{\partial p^{k}}\right)-\ln \left(\frac{q^{k}}{M R S(s(p))_{l}} \frac{\partial M R S(s(p))_{l}}{\partial p^{k}}\right) \\
\Delta \epsilon_{i}=\ln \left(\frac{\left(\frac{q^{k}}{M R S(s(p))_{l}} \frac{\partial M R S(s(p))_{l}}{\partial p^{k}}+\frac{q^{k}}{M R S(s(p))_{j}} \frac{\partial M R S(s(p))_{j}}{\partial p^{k}}-\frac{q^{k}}{\operatorname{MRS}(s(p))_{j}} \frac{\partial M R S(s(p))_{l}}{\partial p^{k}}\right)}{\left(\frac{q^{k}}{M R S(s(p))_{l}}\right)}\right)
\end{array}
$$

which yields

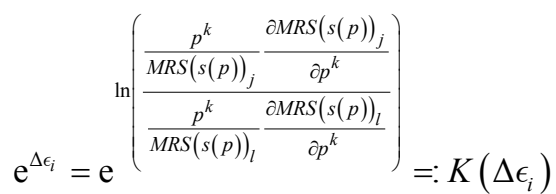


From Equations (6) and (7) we obtain

$$
\begin{aligned}
& K\left(\Delta \epsilon_{i}\right)=\frac{\left(\frac{q^{k}}{\operatorname{MRS}(s(p))_{l}} \frac{\partial M R S(s(p))_{l}}{\partial p^{k}}+\frac{q^{k}}{\operatorname{MRS}(s(p))_{j}} \frac{\partial M R S(s(p))_{j}}{\partial p^{k}}-\frac{q^{k}}{\operatorname{MRS}(s(p))_{l}} \frac{\partial M R S(s(p))_{l}}{\partial p^{k}}\right)}{\frac{q^{k}}{\operatorname{MRS}(s(p))_{l}} \frac{\partial M R S(s(p))_{l}}{\partial p^{k}}} \\
& K\left(\Delta \epsilon_{i}\right) \frac{q^{k}}{M R S(s(p))_{l}} \frac{\partial M R S(s(p))_{l}}{\partial p^{k}} \\
& =\frac{q^{k}}{\operatorname{MRS}(s(p))_{l}} \frac{\partial M R S(s(p))_{l}}{\partial p^{k}}+\frac{q^{k}}{M R S(s(p))_{j}} \frac{\partial M R S(s(p))_{j}}{\partial p^{k}} \\
& -\frac{q^{k}}{M R S(s(p))_{l}} \frac{\partial M R S(s(p))_{l}}{\partial p^{k}} \\
& K\left(\Delta \epsilon_{i}\right) \frac{q^{k}}{M R S(s(p))_{l}} \frac{\partial M R S(s(p))_{l}}{\partial p^{k}}-\frac{q^{k}}{M R S(s(p))_{l}} \frac{\partial M R S(s(p))_{l}}{\partial p^{k}} \\
& =\frac{q^{k}}{M R S(s(p))_{j}} \frac{\partial M R S(s(p))_{j}}{\partial p^{k}}-\frac{q^{k}}{M R S(s(p))_{l}} \frac{\partial M R S(s(p))_{l}}{\partial p^{k}} \\
& \frac{q^{k}}{\operatorname{MRS}(s(p))_{l}} \frac{\partial \operatorname{MRS}(s(p))_{l}}{\partial p^{k}}\left(K\left(\Delta \epsilon_{i}\right)-1\right) \\
& =\frac{q^{k}}{M R S(s(p))_{j}} \frac{\partial M R S(s(p))_{j}}{\partial p^{k}}-\frac{q^{k}}{M R S(s(p))_{l}} \frac{\partial M R S(s(p))_{l}}{\partial p^{k}}
\end{aligned}
$$

Define a new constant $K:=K\left(\Delta \epsilon_{i}\right)-1=\mathrm{e}^{\Delta \epsilon_{i}}-1$, which by substitution and little algebraic manipulation yields

$$
\begin{aligned}
& \frac{q^{k}}{M R S(s(p))_{l}} \frac{\partial M R S(s(p))_{l}}{\partial p^{k}} \\
& =\frac{\frac{q^{k}}{M R S(s(p))_{j}} \frac{\partial M R S(s(p))_{j}}{\partial p^{k}}-\frac{q^{k}}{M R S(s(p))_{l}} \frac{\partial M R S(s(p))_{l}}{\partial p^{k}}}{K}>0
\end{aligned}
$$

The right hand side contracts if $0<K<1$, hence $\mathrm{e}^{\Delta_{\epsilon_{i}}}-1<1$ from which the condition of the theorem follows.

\section{Conclusions}

The paper considers conspicuous ethics as the main driver of ethical consumption. It is assumed that ethical consumers have preferences over the way goods are produced and distributed. This is at variance to the standard economic model, which assumes a preference ordering over the traits of goods. Moreover, in order to reflect the empirically observed positive relationship between prices and demand for ethically produced goods, it is hypothesized that preferences also depend on prices. This is similar to the literature on product quality [2] and 
"snob appeal" [5]. The relative price hypothesis suggests that short-run and long-run demand functions are homogenous of degree zero. This is a desirable property, which permits meaningful welfare analysis [17]. The main result shows that a small perturbation to the price system shifts the preferences of the ethical consumer, suggesting an objective function represented by a prize parameterized direct utility function.

This paper provides a new framework for modelling ethical consumption. Moreover, the formula stated in the main theorem is empirically verifiable. The hypothesis to reject is $\varepsilon \leq 0$, which suggests that ethical preferences do not depend on prices $\varepsilon=0$ or satisfy the usual law of demand $\varepsilon<0$.

Retailers can use this formula to classify ethical consumption goods. The paper suggests a product segmentation and price strategy for retailers using social labels, which provide a price signal and information set about how goods are produced and distributed to a group of informing consumers whose willingness to pay is high.

\section{Conflicts of Interest}

The authors declare no conflicts of interest regarding the publication of this paper.

\section{References}

[1] Veblen, T. (1899) The Theory of the Leisure. Macmillan, New York.

[2] Pollak, R.A. (1977) Price Dependent Preferences. American Economic Review, 67, 64-75.

[3] Alcaly, R.E. and Klevorick, A.K. (1970) Judging Quality by Price, Snob Appeal, and the New Consumer Theory. Zeitschrift fur National"okonomie, 30, 53-64. https://doi.org/10.1007/BF01289992

[4] Samuelson, P.A. (1947) Foundations of Economic Analysis. Harvard University Press, Cambridge, MA.

[5] Scitovsky, T. (1944) Some Consequences of the Habit of Judging Quality by Price. Review of Economic Studies, 12, 100-105. https://doi.org/10.2307/2296093

[6] Tallontire, A. and Blowfield, M. (2001) Ethical Consumers and Ethical Trade: A Review of Current Literature. Policy Series, 12, 1-35.

[7] Doane, D. (2001) Taking Flight: The Rapid Growth of Ethical Consumerism. New Economics Foundation, London.

[8] Basu, A. and Hicks, R. (2008) Label Performance and the Willingness to Pay for Fair Trade Coffee: A Cross-National Perspective. Working Paper 125, Center for Development Research, University of Bonn, Bonn.

[9] Driesen, L., Pelsmacker, P. and Rayp, G. (2005) Do Consumers Care about Ethics? Willingness to Pay for Fair-Trade Coffee. The Journal of Consumer Affairs, 39, 363-385. https://doi.org/10.1111/j.1745-6606.2005.00019.x

[10] Loureiro, M. and Lotade, J. (2005) Do Fair Trade and Eco-Labels in Coffee Wake Up the Consumer Conscience? Ecological Economics, 53, 129-138. https://doi.org/10.1016/j.ecolecon.2004.11.002

[11] Northey, J., Cranfield, J., Henson, S. and Masakure, O. (2010) An Assessment of 
Consumer Preferences for Fair Trade Coffee in Toronto and Vancouver. Agribusiness, 26, 307-325. https://doi.org/10.1002/agr.20217

[12] Cailleba, P. and Casteran, H. (2009) A Quantitative Study on the Fair Trade Coffee Consumer. Journal of Applied Business Research, 25, 31-46.

[13] Cash, S.B., Arnot, C. and Boxal, P.C. (2006) Do Ethical Consumers Care about Price? A Revealed Preference Analysis of Fair Trade Coffee Purchases. Canadian Journal of Agricultural Economics, 54, 555-565. https://doi.org/10.1111/j.1744-7976.2006.00066.x

[14] Mupandawana, M., Liu, Y., Yang, S.H. and Hu, W. (2012) Consumer Willingness to Pay for Fair Trade Coffee: A Chinese Case Study. Journal of Agricultural and Applied Economics, 44, 21-34. https://doi.org/10.1017/S1074070800000146

[15] Andorfer, V.A. and Liebe, U. (2012) Research on Fair Trade and Consumption-A Review. Journal of Business Ethics, 106, 415-435. https://doi.org/10.1007/s10551-011-1008-5

[16] Fechner, G.T. (1988) Ueber die psychischen Massprinzipien und das Webersche Gesetz. Philosophische Studien, 4, 161-230.

[17] Kalman, P.J. (1968) Theory of Consumer Behavior When Prices Enter the Utility Function. Econometrica, 36, 497-510. https://doi.org/10.2307/1909519 